\section{Serum trypsin concentrations in diabetes mellitus}

Abnormalities in exocrine pancreatic function occur in patients with diabetes mellitus and their prevalence is particularly high in insulindependent diabetics. ${ }^{1}$ Measurement of serum trypsin is a relatively simple test of exocrine pancreatic function. ${ }^{2}$ We therefore undertook a study of serum trypsin concentrations in diabetic patients.

\section{Patients, methods, and results}

Fifty patients (age range 14-65 years) with diabetes mellitus were studied; none of them had clinical evidence of chronic pancreatitis, chronic diarrhoea, or renal dysfunction. Duration of diabetes ranged from two weeks to 30 years. Patients were classified according to type of treatment: 25 were insulindependent diabetics; 15 were treated with sulphonylureas, including two newly discovered diabetics; in 10 patients, including one new patient, diabetes was stabilised with biguanides. Seventy-six healthy subjects and 20 hospitalised patients without pancreatitis, diabetes, or other gastrointestinal disease served as controls.

Serum trypsin concentration was measured by radioimmunoassay, by a double-antibody technique. ${ }^{2}$ Highly purified trypsin was used for iodination and as an immunogen. Antibody was raised in rabbits. Iodination was carried out with chloramine. Within-assay variance was $7.5 \%$ at low concentrations and $2.7 \%$ at high concentrations. Repeat trypsin measurements in the same patients under similar conditions varied less than $20 \%$ at low trypsin concentrations. Blood samples were obtained at around $11 \mathrm{am}$, roughly two to three hours after breakfast and the injection of insulin or the intake of oral hypoglycaemic agents. Samples were allowed to clot, centrifuged, and the sera stored at $-20^{\circ} \mathrm{C}$ until assay.

Eighteen out of 25 insulin-dependent diabetics had subnormal trypsin concentrations. The mean serum trypsin concentration in the insulin-dependent patients was subnormal and was also significantly lower $(P<0.005)$ than that in patients treated with sulphonylureas (figure). Four out of 15 patients treated with sulphonylureas also had subnormal trypsin concentrations; the mean for this group was in the low-normal range. Serum trypsin concentration in the group treated with biguanides was similar to that in the normal subjects, and was significantly greater than that in patients who received sulphonylureas $(\mathrm{P}<0.05)$.

\section{Comment}

We found that serum trypsin concentrations were lowest and subnormal concentrations were more prevalent in insulin-dependent diabetics; trypsin concentrations were intermediate in patients treated with sulphonylureas; and no different from the controls in those treated with biguanides. This suggests that the degree of

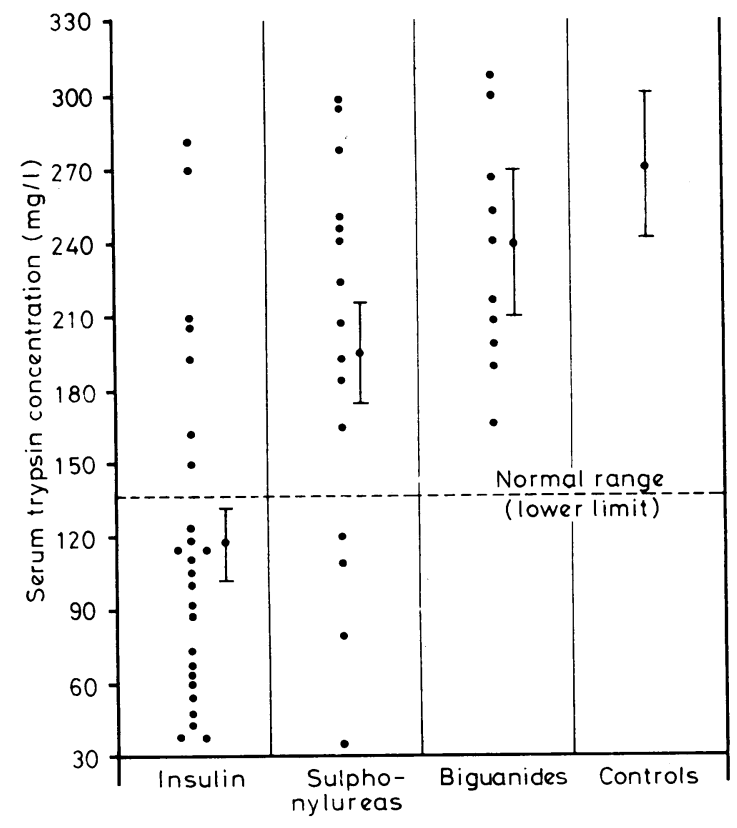

Serum trypsin concentrations in patients with diabetes mellitus (classified according to mode of treatment) and in 96 controls. exocrine pancreatic deficit in diabetes parallels the endocrine betacell deficit. On the basis of the Lundh test a similar high prevalence of exocrine pancreatic abnormality was observed in insulin-dependent diabetics. ${ }^{1}$ The magnitude of this abnormality is inversely related to beta-cell reserve as reflected in C-peptide concentrations. ${ }^{3}$ Our observations extend this phenomenon to non-insulin-dependent diabetics.

None of our patients had diarrhoea or clinical malabsorption, despite having serum trypsin concentrations lower than those found in some patients with chronic pancreatitis with malabsorption. Since steatorrhoea is responsible for the diarrhoea in patients with malabsorption, it would be interesting to investigate whether pancreatic lipase secretion alters in parallel with that of trypsin. Equally perplexing is the possible mechanism underlying subnormal exocrine function in diabetes in view of the paucity of histological changes in the exocrine pancreas of diabetes. Nevertheless, some necropsy data suggest that the pancreas in insulin-dependent diabetics is smaller than in normal subjects, ${ }^{4}$ and that the pancreas may be heavily infiltrated with fat ${ }^{5}$ or with fibrous tissue. ${ }^{4}$

We conclude that serum trypsin concentration seems to be an easily measurable marker of exocrine pancreatic function in diabetes exocrine pancreatic function as shown by serum trypsin measurements seems to parallel pancreatic beta-cell activity; and exocrine pancreatic dysfunction in diabetes may be related to pancreatic size and may be an integral component of the pathogenesis of type I diabetes mellitus.

${ }^{1}$ Frier, B M, et al, Gut, 1976, 17, 685.

${ }^{2}$ Elias, E, Redshaw, M, and Wood, T, Lancet, 1977, 2, 66.

${ }^{3}$ Frier, B M, et al, Diabetologia, 1978, 14, 301.

4 Doniach, I, and Morgan, A G, Clinical Endocrinology, 1973, 2, 233.

${ }^{5}$ Herxheimer, G, et al, Verhandlungen der Deutschen Gesellschaft für Verdaunng- und Stoffwechselkrankheiten, 1932, 11, 112.

(Accepted 20 September 1978)

Royal Free Hospital, London NW3 2QG

$P$ DANDONA, DPHIL, MRCP, director of metabolic unit and senior lecturer in chemical pathology

E ELIAS, MB, MRCP, lecturer, academic department of medicine A G BECKETT, MB, FRCP, consultant physician

\section{Tinel's sign and the carpal tunnel syndrome}

Jules Tinel ${ }^{12}$ described that tapping the proximal stump of an injured nerve may produce a tingling sensation (fourmillement) in its cutaneous distribution. He concluded that this indicated axonal regeneration. The value of Tinel's sign in assessing nerve injuries has been much debated. ${ }^{3} \mathrm{He}$ did not mention using his sign in relation to entrapment neuropathies. Nevertheless, many standard textbooks state that it is of value in diagnosing the carpal tunnel syndrome (CTS). Since this was contrary to our impression we carried out the following investigation.

\section{Patients, methods, and results}

Fifty-one hands affected by CTS which was not secondary to trauma or any localised or generalised disease were compared with normal hands of a group matched for age and sex. Many of the control hands were the asymptomatic contralateral hands of patients with CTS. Persons with diabetes mellitus or peripheral neuropathy were excluded. Sensory recordings were made with either needle or surface electrodes after stimulating the index finger with ring electrodes. Abnormal or doubtful potentials were measured by averaging 16 to 32 responses. Motor latencies were measured by standard techniques. The tests were made in a room with a controlled temperature of $20-22^{\circ} \mathrm{C}$. The diagnostic criteria for CTS were the presence of three or more of the following: (1) sensory signs in the distribution of the median nerve in the hand; (2) thenar wasting or weakness; (3) a median nerve motor latency after stimulation at the wrist greater than $4.5 \mathrm{~ms}$; (4) a latency of greater than $2 \cdot 7 \mathrm{~ms}$ to the onset of the median sensory action potential, with the distance between the stimulating and recording electrodes corrected to $10 \mathrm{~cm}$; (5) a median nerve sensory action potential at the wrist of less than $8.6 \mu \mathrm{V}$.

Patients and controls also had to have an ipsilateral ulnar sensory action 
potential at the wrist of at least $8.5 \mu \mathrm{V}$ with a latency of less than $2.8 \mathrm{~ms}$. Tinel's sign, sought by tapping the volar aspect of the wrist with a finger, was regarded as positive when tingling or mild electric shock sensations were felt in the median nerve territory in the hand. The data (see table) were arranged in a $2 \times 2$ contingency table and a $\chi^{2}$ test performed.

Presence of Tinel's sign in hands with and without CTS

\begin{tabular}{|c|c|c|c|c|c|}
\hline & & & & With CTS & Without CTS \\
\hline $\begin{array}{l}\text { No of hands } \\
\text { No of subjects } \\
\text { Age range (years) } \\
\text { Mean age (years) } \\
\% \text { Women ... } \\
\text { Tinel's sign present }\end{array}$ & $\begin{array}{l}\cdots \\
\cdots \\
\cdots \\
\cdots\end{array}$ & $\begin{array}{l}\cdots \\
\cdots \\
\cdots \\
\cdots\end{array}$ & $\begin{array}{l}\cdots \\
\cdots \\
\cdots \\
\cdots\end{array}$ & $\begin{array}{l}51 \\
37 \\
36-84 \\
55 \\
81 \\
23(45 \%)^{*}\end{array}$ & $\begin{array}{l}52 \\
38 \\
30-84 \\
53 \\
79 \\
15(29 \% \text { o })^{*}\end{array}$ \\
\hline
\end{tabular}

$\chi^{2}=2 \cdot 26 ; P=0 \cdot 10$

\section{Comment}

The popularity of Tinel's sign as applied to CTS is probably attributable to Phalen, ${ }^{4}$ who found it present in $73 \%$ of 621 hands with alleged CTS. None of his patients, however, had electrodiagnostic confirmation. Only $40 \%$ of the hands underwent decompression, the others improving with conservative measures. Thus confirmation by exploration was impossible in the majority. Furthermore, it is unusual for $60 \%$ of hands with CTS to recover without decompression. There is, therefore, some uncertainty about how many of Phalen's patients had CTS. So far as we know neither Phalen nor anyone else has systematically examined a series of normal hands for the presence of Tinel's sign, although Hamlin and Lehman ${ }^{5}$ state simply that it may occur in the absence of CTS. Even trivial pressure on a normal ulnar nerve at the elbow will often produce tingling in the ulnar innervated part of the hand. The same occurs with normal median nerves at the wrist, although less commonly, presumably because of the partial protection afforded by the thick transverse carpal ligament. Our findings show that compression of the median nerve in the carpal tunnel does not add appreciably to its sensitivity. We therefore conclude that this adaptation of Tinel's sign is of no diagnostic value.

Requests for reprints should be addressed to: Professor J D Stewart, Montreal General Hospital, Division of Neurology, 1650 Cedar Avenue, Montreal, Quebec H3G 1A4, Canada.

1 Tinel, J, Presse Médicale, 1915, 47, 388.

2 Wilkins, R H, and Brody, I A, Archives of Neurology, 1971, 24, 573.

${ }^{3}$ Sunderland, S, Nerves and Nerve Injuries, London, E and S Livingstone, 1968.

4 Phalen, G S, fournal of Bone and foint Surgery, 1966, 48-A, No 2, 211.

5 Hamlin, E, and Lehman, R A W, New England fournal of Medicine, 1967, 276, 849 .

(Accepted 1 August 1978)

Department of Neurology and Neurosurgery, McGill University, and Montreal Neurological Institute, Montreal, Quebec H3A 2B4, Canada

J D STEWART, MRCP, $\operatorname{FRCP}(\mathrm{C})$, assistant professor

A EISEN, MD, $\operatorname{FRCP}(\mathrm{C})$, associate professor

\section{Timing of female sterilisation}

Female sterilisation as a method of contraception is increasing. It is now one of the most common gynaecological operations in the West Midlands. The decision to sterilise seems often to be reached in haste with inadequate counselling and at a time when the woman can least make a well-balanced judgment, such as immediately before or after delivery. We investigated whether the timing of sterilisation affected its outcome and its relationship to satisfaction with the operation.

\section{Patients, methods, and results}

Two groups of women were followed up for two to seven years after sterilisation. Eighty had been sterilised at caesarean section and 105 between the second and fifth days postpartum. We visited them at their homes. Full histories were taken, with particular emphasis on the reasons for sterilisation, who had suggested the operation, the outcome, and subsequent satisfaction. The patients were divided in to three groups: those who were entirely satisfied with the operation, those who deeply regretted their original decision, and those who had significant regrets, which they related to sterilisation, but who basically stood by their decision. The last were placed in a "relatively dissatisfied" group. We used the same method when examining 151 interval sterilisations, and the patients in that study were used for comparison. ${ }^{1}$

The average age at sterilisation was 28.6 years, no woman had fewer than two children, and all social classes were represented. None of these factors was significantly associated with dissatisfaction. Most sterilisations were done for socioeconomic reasons, although one-third of the caesarean section group were recommended the operation solely because they had had two or more previous sections. The level of satisfaction with the operation was compared with that among the interval group (table). Rates of dissatisfaction in the postpartum and caesarean section groups were $8.7 \%$ and $11.4 \%$ respectively.

Results compared with those after interval sterilisation

\begin{tabular}{l|c|c|c|c} 
& $\begin{array}{c}\text { Caesarean } \\
\text { section }\end{array}$ & Postpartum & Interval & Total \\
\hline $\begin{array}{l}\text { Satisfied } \\
\text { Relatively dissatisfied }\end{array}$ & 62 & 77 & 146 & 285 \\
$\begin{array}{l}\text { Dissatisfied } \\
\text { Total }\end{array}$ & 7 & 16 & 0 & 27 \\
\hline & 80 & 12 & 5 & 24 \\
\hline
\end{tabular}

$\chi^{2}=34 \cdot 14 . \quad P=0.001$

These rose to $26.7 \%$ and $22.5 \%$ if the "relatively dissatisfied" were included. The level of dissatisfaction in the interval group was $3.3 \%$ and there were no "relatively dissatisfied." One-third of all operations were recommended by doctors. Of the "dissatisfied," all were suggested by a doctor in the caesarean section group, and $75 \%$ in the postpartum group. Histories of manifest psychiatric illness did not adversely affect outcome. Nevertheless, the six with severe personality disorders were represented exclusively in the "relatively dissatisfied" and "dissatisfied" groups.

\section{Comment}

The greater the interval from any obstetric event the better were the results of sterilisation. Only $1 \%$ of women regretted sterilisation when performed by laparoscopy at a varying interval from the last confinement. ${ }^{2}$ This low incidence is comparable with our own results after interval sterilisation. The increased incidence of dissatisfied patients which we found in the caesarean section and postpartum groups complements the findings of Winston ${ }^{3}$ in 103 patients seeking reversal of sterilisation, two-thirds of whom had been sterilised immediately after pregnancy. There was also a high incidence of relatively dissatisfied patients in postpartum and caesarean section groups, and, although these patients eventually felt they had made the right decision, much distress could have been avoided by performing the operation at a later date. In all cases interval sterilisation could have been recommended.

Previous psychiatric illness should be no contraindication to sterilisation, but women with severe personality disorders are likely to be dissatisfied. This probability has to be weighed against the often clear social advantages of recommending sterilisation. An increasing number of younger women are being sterilised, but there is no evidence of a disproportionate number among them who regret the operation. More regret is expressed by those to whom doctors recommend sterilisation, and that raises a serious objection to this common practice. The need for both partners to be counselled before performing sterilisation cannot be too strongly emphasised.

${ }^{1}$ Sim, M, Emens, J M, and Jordan, J A, British Medical fournal, 1973, 3, 220.

2 Watkins, R A, et al, Medical fournal of Australia, 1976, 2, 251.

3 Winston, R M L, British Medical fournal, 1977, 2, 305.

(Accepted 18 August 1978)

Birmingham Maternity Hospital, Birmingham B15 2TG

J MICHAEL EMENS, MB, MRCOG, senior registrar

All Saints' Hospital, Birmingham B18 5SD

J EDWARD OLIVE, MB, MRCPSYCH, senior registrar 